\title{
MAPPING THE EFFECTS OF AGRICULTURAL DEVELOPMENT TO WATER YIELD USING REMOTE SENSING
}

\author{
Babangida Ba iya ${ }^{1,2,3}$, Mazlan Hashim ${ }^{1,2 *}$ \\ ${ }^{1}$ Faculty of Built Environment \& Surveying, Universiti Teknologi Malaysia, Johor Bahru, Malaysia \\ ${ }^{2}$ Geoscience and Digital Earth Centre (INSTeG), Research Institute of Sustainability Environment (RISE), Universiti \\ Teknologi Malaysia, Johor Bahru, Malaysia \\ babangidabaiya@gmail.com, mazlanhashim@utm.my \\ ${ }^{3}$ Federal Polytechnic, Mubi, Adamawa State, Nigeria.
}

KEY WORDS: Agriculture, forest, water yield, land use change, river basin

\begin{abstract}
:
Variation of land cover status, like clearance of forest for agricultural (oil palm) plantation activities, may lead to rapid landscape development. Also, it may cause climate variation effects like excessive rainfall and flooding, which may result in loss of properties and lives. Agricultural (oil palm) plantation's dispersed canopy and the open surface of the ground compared to primary forest cause much more runoff and streamflow or discharge. Hence, this paper analyses the land-use changes and evaluate its influence on water yield using the Soil Water Assessment Tools model. Quantitative and qualitative assessment to examine the successive variation from forest to agriculture has been carried out between 2000 and 2010. The results indicate that the conversion of forest to agriculture has a significant influence on hydrological properties of the study area, which cause average water yield increase by $1.93 \%$ in the area between 2000 and 2010. Which, in turn, can lead to dryer during the dry season and wetter during rainy seasons. Furthermore, forest and water body are directly proportional. Similarly, forest and agriculture are inversely proportional with R2 > $0.85, \mathrm{p}=0.001$. The study shows the ability of Landsat in monitoring the assessment of forest to agriculture, which causes changes in hydrology. This study offers a useful input of planning and sustainable management of surface and water resources
\end{abstract}

\section{INTRODUCTION}

\subsection{Background of the study}

Agricultural landscape developments, namely various scales of plantation activities, have a significant effect on hydrological responses; it is known due to the extent and incidence of flooding (Yu et al., 2019). In the early years the sub-watershed of Sayong river basin mostly forested, recently the forest now converted to agricultural (oil palm). The land use/land cover changes transform the natural forest, which increases the occurrence of flooding in the study area. Agriculture and urban settlement are gradually taking over the forested areas. Many researchers made it well known that clearing of forest for agriculture will finally disturb the efficient of the hydrological cycle (Shiferaw et al., 2018; Marengo et al., 2018; Shukla and Gedam, 2018). Hence, the usual hydrological cycle's surface runoff, groundwater quality and quantity. Also, stream water quality, streamflow, evapotranspiration, soil infiltration and interception will change as the forest is cleared (Keleş, 2018).

Usually, the agricultural (oil palm) and urban are gradually taking over the forested areas that lead to the diminishing of forest areas across Peninsula Malaysia (Mahmud and Hashim, 2010). The urbanization has significant economic growth. As well, development has some influence on the environment like deforestation and agricultural expansion (Musa and Hashim, 2017). Therefore, changes in surface water. As a result of changes from forest to agriculture, may lead to high risk of flooding, which may result to an outbreak of waterborne diseases and in turn lead to loss of lives (Fahey et al., 2010).

However, urbanization and agriculture have significant benefits in terms of economic development and the availability of food.
Then again, the destructive consequences of floods are well known, which causes loss of lives and properties (Talbot et al., 2018). Nevertheless, agricultural (oil palm) remains the backbone of the Malaysian economy and structural development. Though, clearing of the forest will disturb the efficiency of the hydrological cycle in the area. Expansion of urban and agricultural (oil palm) is the leading effect of land use variation, which results to decrease in the forest (Lei and $\mathrm{Zhu}, 2018$ ). As a result of urban growth, the natural forest is being converted to build-up areas. Hence, monitoring and data delivery on the changes are highly significant for policy and decision-making processes (Yildirim et al., 2011).

Previous studies demonstrated the influence of conversion of forest on water yield for some humid tropical countries (Barrios et al., 2018). Rainforest conversion to other land uses in Germany, the United Kingdom and Nairobi Kenya (Mwangi et al., 2016). Consequently, increased in water yield afterwards was revealed (Ebrahimian et al., 2016). Also, Keleş, (2018) report that an increase in water yield resulted from forest clearcuttings. Furthermore, some recent research support that the conversion of forest to young plantations decreases evapotranspiration (ET) and infiltration rates (Dislich et al., 2017; Manoli et al., 2018). Water storage reduces as a result of the decrease of infiltration (Berkelmann et al., 2018) and leads to increase in surface runoff (Duan and Cai, 2018) possibly endangering the access to available water and increase the risk of flooding. Though, this study needs to be widened to cover other essential sub-watersheds to improve planning and management of land-use change in the study area.

Furthermore, the effect of land use changes on hydrology varies from place to place; therefore, conducting the study at the local scale is highly needed. Urban authorities are responsible for 
making budget and plan for the management of land and some other resources to meet up with the demand for infrastructural needs (Sperling and Ramaswami, 2017). Understanding the effect of land use/land cover changes, on hydrological is highly needed for proper management of water resources. To support sustainable development goal (SDG) 6 of target 6.1 and 6.4, which stress the need to bring the end of global water scarcity by 2030 . Efficient and effective management of the river basin is highly significant to guarantee the availability of water and demand for domestic consumption (Kahlerras, 2018).

Also, restoration of forest, wetland and grassland as a naturalbased solution for water quality and quantity (Report on water day 22nd March 2018). Will contribute meaningfully to the achievement of SDG 6, of target 6.1 and 6.2 , which stress the need, to bring the end of water scarcity by 2030 . Therefore, this study analyses the land-use changes and evaluate its influence on water yield using the Soil Water Assessment Tools model. "The hypothesizes assumed that the land-use changes in any watershed, which impacted on water yield could systematically map and analyze using satellite-based remote sensing.

\section{MATERIALS AND METHODS}

\subsection{Study Area}

The study area (Sayong sub-watershed) is in the north-western part of Johor, Sayong rivers are the major tributaries of river Johor. The land use of the study area includes the following: forest, urban, oil palm and agriculture. The study area lies between latitude $1^{\circ} 43^{\prime} 30^{\prime \prime}$ and $1^{\circ} 57^{\prime} 00{ }^{\prime \prime} \mathrm{N}$ and Longitudes $103^{\circ} 21^{\prime}$ and $103^{\circ} 39^{\prime} 00^{\prime \prime} \mathrm{E}$.

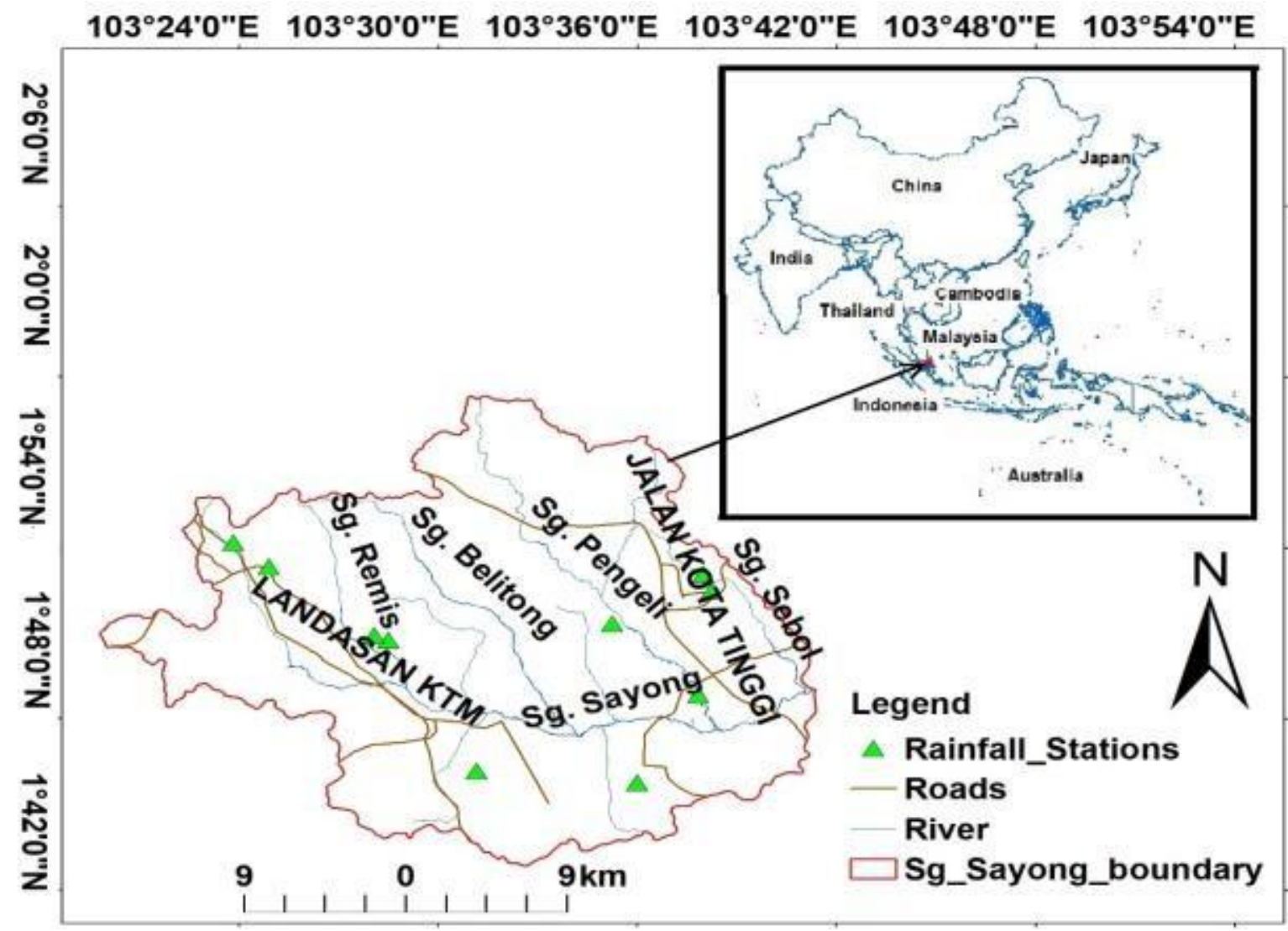

Figure 1. Sayong sub watershed

\subsection{Materials}

The Landsat 7 enhanced thematic mapper plus (ETM+) is the primary data sets used in the study. These ETM+ sets are acquired for three epochs 2000, 2005 and 2010; was classified to derive to land use maps and later used in the land-use change analysis. This is achieved using ArcMap v10.3 GIS system where these ETM+ data sets have to undergo data pre- processing, image classification and post-processing for land use change analysis. The land-use types of the study area is classified into four classes, namely; oil palm, forest, urban and water body. Qualitative and quantitative evaluation. to analyze the successive changes from forest to agricultural oil palm for water yield was carried out for the periods of 2000, 2005 and 2010 (figure 2). 


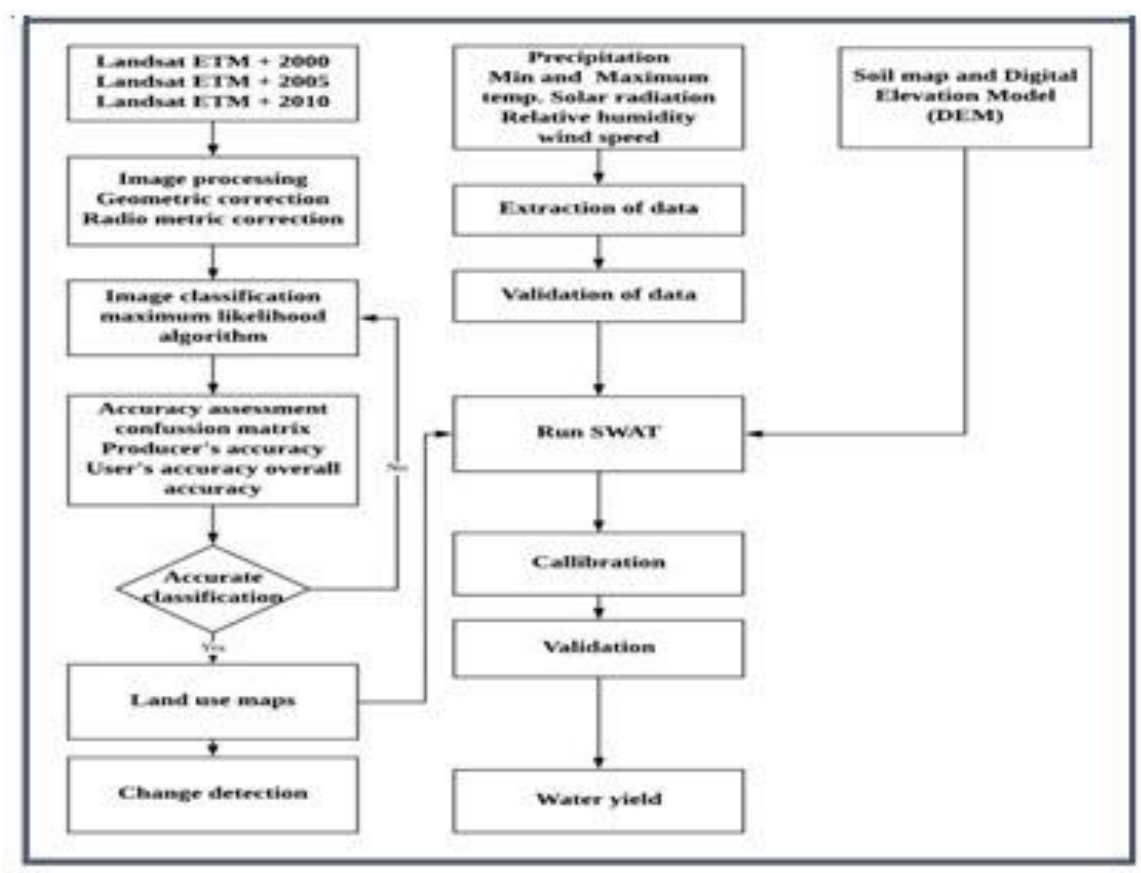

Figure 2. Methodology flow chart

In pre-processing: satellite digital number (DN) converted to radiance, atmospheric and geometric correction were carried out. The rectified images were classified using the maximum likelihood algorithm by supervised classification method; also, the error matrix employed in accuracy evaluation.

Furthermore, the factors that influence water yield include; topography, soil, vegetation and climate (Wang et al., 2017). Hence, this study evaluates the effects of the conversion of forest to agricultural plantation (oil palm) to water yield using soil water assessment tools (SWAT) model, expressed as follows

$$
S W_{t}=S W_{0}+\sum_{i=1}^{t}\left(R_{\text {diny }}-Q_{\text {gurf }}-E_{a}-W_{\text {gesp }}-Q_{g W}\right)
$$

Where,

$\mathrm{SW}_{\mathrm{t}}=$ Final soil water content $\left(\mathrm{mm} \mathrm{H}_{2} \mathrm{O}\right)$

$\mathrm{SW}_{\mathrm{o}}=$ Initial soil water content on dayi $\left(\mathrm{mm} \mathrm{H}_{2} \mathrm{O}\right)$

$\mathrm{t}=$ time (days) During modelling process

$\mathrm{R}_{\text {day }}=$ amount of Precipitation on dayi $\left(\mathrm{mm} \mathrm{H}_{2} \mathrm{O}\right)$

$\mathrm{Q}_{\text {surf }}=$ amount of surface runoff on dayi $\left(\mathrm{mm} \mathrm{H}_{2} \mathrm{O}\right)$,

$\mathrm{E}_{\mathrm{a}}=$ amount of evapotranspiration on dayi $\left(\mathrm{mm} \mathrm{H}_{2} \quad \mathrm{O}\right)$

$\mathrm{Qgw}=$ the measure of groundwater discharge in day $\mathrm{I}(\mathrm{mm})$ and Wseep=is the measure of water entering the vadose zone from the soil profile on day I $(\mathrm{mm})$
The Soil Water Assessment Tools (SWAT) model employed due to the fact that it has wide range of coverage in evaluation of water properties in the past, current and future, applied land use which affect evapotranspiration, the ability of the model to carry out calibration easily, is freely available in the internet and it is flexible and user friendly

\section{RESULTS AND DISCUSSION}

The results include land-use changes detection and water yield of the study area, as explained below:

\subsection{Classification of Image and Accuracy Assessment}

Classification carried out using three sets of images; training samples were generated using maximum likelihood classifier through supervised classification. The four land use land cover classified includes; oil palm, forest, urban and water body. The accuracy of the classification was evaluated and validated by means error matrix. The accuracy has ascertained with the help of handheld GPS through field validation. Table 1 present the classified images with their overall accuracies/kappa indexes.

Table. 1: Producer's, user's and overall accuracies of the classified images (in percentages)

\begin{tabular}{|c|c|c|c|c|c|c|}
\hline \multirow[t]{2}{*}{ LULC } & \multicolumn{2}{|c|}{2000} & \multicolumn{2}{|c|}{2005} & \multicolumn{2}{|c|}{2010} \\
\hline & $\begin{array}{l}\text { Producer's } \\
\text { accuracy } \\
(\%)\end{array}$ & $\begin{array}{l}\text { User's } \\
\text { accuracy } \\
(\%)\end{array}$ & $\begin{array}{l}\text { Producer's } \\
\text { accuracy } \\
(\%)\end{array}$ & $\begin{array}{l}\text { User's } \\
\text { accuracy } \\
(\%)\end{array}$ & $\begin{array}{l}\text { Producer's } \\
\text { accuracy } \\
(\%)\end{array}$ & $\begin{array}{l}\text { User's } \\
\text { accuracy } \\
(\%)\end{array}$ \\
\hline Oil Palm & 88.32 & 84.81 & 85.07 & 86.42 & 80.67 & 86.32 \\
\hline Forest & 89.23 & 96.00 & 82.00 & 89.00 & 79.61 & 83.00 \\
\hline Urban & 95.00 & 88.00 & 88.04 & 85.91 & 85.61 & 95.00 \\
\hline Water Body & 89.76 & 93.76 & 93.08 & 88.53 & 90.56 & 92.87 \\
\hline $\begin{array}{l}\text { Overall } \\
\text { accuracy }\end{array}$ & \multicolumn{2}{|c|}{91.08} & \multicolumn{2}{|c|}{88.05} & \multicolumn{2}{|c|}{85.02} \\
\hline
\end{tabular}


The International Archives of the Photogrammetry, Remote Sensing and Spatial Information Sciences, Volume XLII-4/W16, 2019 6th International Conference on Geomatics and Geospatial Technology (GGT 2019), 1-3 October 2019, Kuala Lumpur, Malaysia

The evaluation of the accuracy shows that the required range of more than $85 \%$ and ascertained by the kappa index range of more 0.85 ; hence showing good image classification of the image sets

\subsection{Land use changes analysis}

The Landsat ETM+ for the creation of land use maps of 2000, 2005 and 2010 were applied Figure 4. The land use/land cover classified into four classes: oil palm, forest, urban and water.

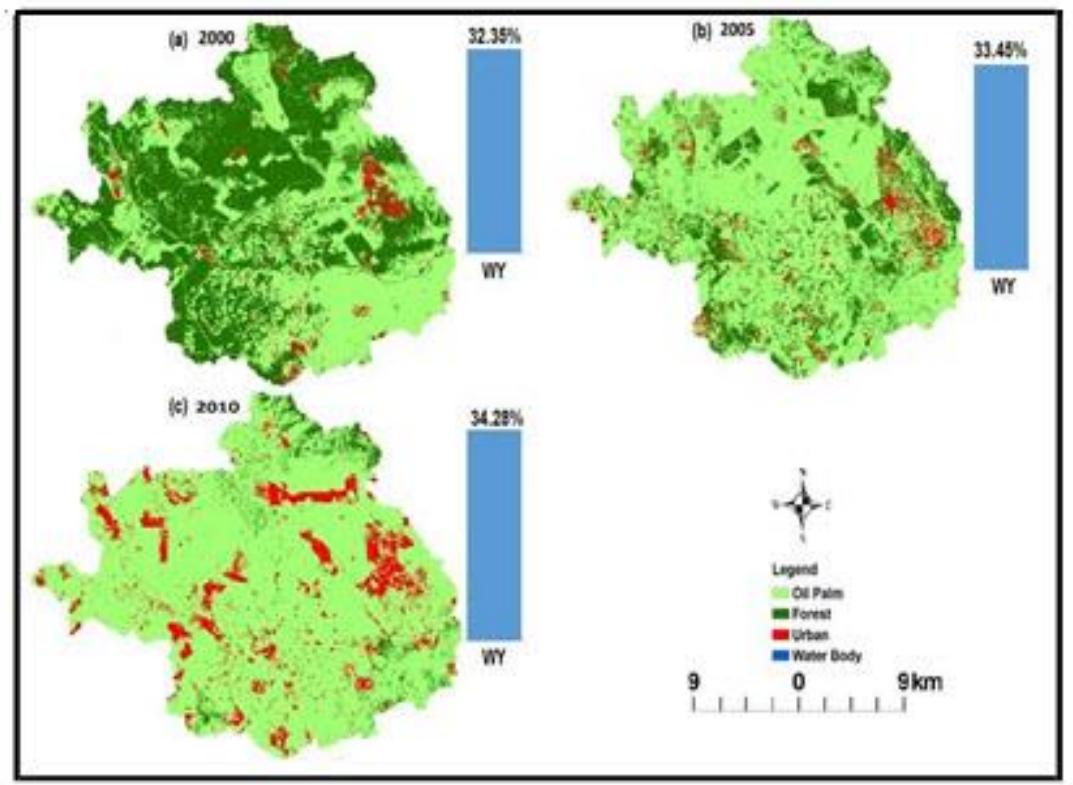

Figure 3. Land Use Classes and WY (a) 2000, (b) 2005 and (c) 2010

Any additional supporting data may be appended, provided the paper does not exceed the limits given above. The forest with the total area of 34901.20 ha, which is approximately $50.37 \%$, has the most leading occupancy in the study area for the year 2000. Figure 4 shows the various percentages of land use changes over time inform of a histogram.

Oil palm increased from $46.51 \%$ in 2000 to $74.26 \%$ in 2005 and $84.70 \%$ in 2010 . Though, about 34901.20 ha, which represents $50.37 \%$ of the forest in 2000 . However, in 2005 the forest reduced to $14791.00 \mathrm{ha}$, representing $21.35 \%$ of the total area.
Also, in 2010 it decreased to 2794.77 ha, representing only $4.03 \%$. Likewise, the water body was $0.06 \%$ in 2000 . Subsequently, in 2010 the water body decreased to $0.01 \%$. These indicate that the forest has declined considerably within 11 years, while oil palm increased significantly within 11 years.

These variations were substantial, and it has a significant influence on water resources in the study area, which may lead to an increase in flood occurrences (Pervez and Henebry, 2015).

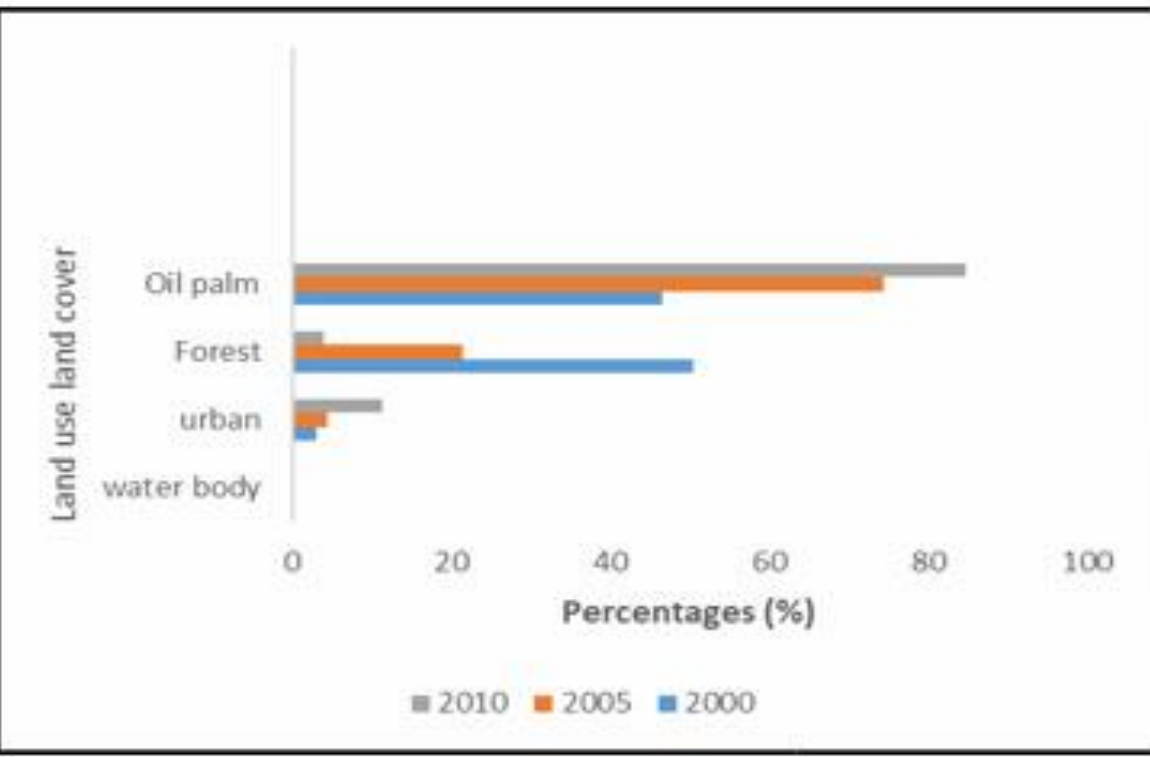

Figure 4. Percentages LULC classes of 2000, 2005 and 2010 


\subsection{Correlation of variables}

To ascertain the relationship between oil palm and water body, forest and water body, and forest and oil palm, equation 2 of Spearman correlation was applied. Spearman considered 1 as positive correlation, -1 as a negative correlation and 0 stands for no correlation. The results indicate that: oil palm and water body (Table 3a) has a negative correlation with $\mathrm{R}^{2}=-1$, forest and water body (Table $3 \mathrm{~b}$ ) has a positive linear relationship with $\mathrm{R}^{2}=1$.

$$
P=1-\frac{6 \sum D^{2}}{n^{3}-n}
$$

Where $\mathrm{P}$ is the spearman rank correlation,

$\mathrm{R}$ is the ranks of variables,

$\mathrm{D}$ is the difference between the ranks of corresponding variables and $\mathrm{n}$ is the number of observations.

Similarly, forest and oil palm (Table 3c) have a negative linear relationship with $\mathrm{R}^{2}=-1$. therefore, land use/land cover variations were found to have a substantial influence on water quality and quantity through statistical analysis, spatial analysis, and hydrological modelling (Yildirim et al., 2011).

(a) Table. 3: Spearman correlation between; a) oil palm and water yield, b) forest and water yield c) forest and oil palm

\begin{tabular}{|c|c|c|c|c|c|c|}
\hline S/No. & Oil Palm (\%) & $\mathbf{R}_{1}$ & Water yield (\%) & $\mathbf{R}_{2}$ & $\mathrm{D}\left(\mathbf{R}_{\mathbf{1}}-\mathbf{R}_{\mathbf{2}}\right)$ & $\mathbf{D}^{2}$ \\
\hline 1 & 46.51 & 3 & 38.00 & 1 & 2 & 4 \\
\hline 2 & 74.26 & 2 & 33.31 & 2 & 0 & 0 \\
\hline 3 & 84.70 & 1 & 24.69 & 3 & 2 & 4 \\
\hline \multicolumn{7}{|l|}{ (b) } \\
\hline S/No. & Forest (\%) & $\mathbf{R}_{1}$ & Water yield (\%) & $\mathbf{R}_{2}$ & $\mathrm{D}\left(\mathbf{R}_{1}-\mathbf{R}_{2}\right)$ & $\mathbf{D}^{2}$ \\
\hline 1 & 50.37 & 1 & 38.00 & 1 & 0 & 0 \\
\hline 2 & 21.30 & 2 & 33.31 & 2 & 0 & 0 \\
\hline 3 & 4.03 & 3 & 24.69 & 3 & 0 & 0 \\
\hline \multicolumn{7}{|l|}{ (c) } \\
\hline S/No. & Forest (\%) & $\mathbf{R}_{1}$ & Oil palm (\%) & $\mathbf{R}_{2}$ & $\mathbf{D}\left(\mathbf{R}_{1}-\mathbf{R}_{2}\right)$ & $\mathrm{D}^{2}$ \\
\hline 1 & 50.37 & 1 & 46.51 & 3 & -2 & 4 \\
\hline 2 & 21.30 & 2 & 74.26 & 2 & 0 & 0 \\
\hline 3 & 4.03 & 3 & 84.70 & 1 & 2 & 4 \\
\hline
\end{tabular}

\subsection{Analysis of water yield}

The average monthly water yield of the study area for the year 2000, 2005 and 2010 (Figure 5) indicate a successive gradual increase in water yield. Each watershed produces various water yield patterns, showing the amount and fluctuation of runoff. The result is similar to the previous studies (Rizaludin Mahmud and Hashim, 2010), which utilized water balance scheme.

The study area has a maximum water yield on the northeast monsoon period from November to February, where December is the peak harvest period of the water yield from 2000 to 2010 (Figure 5). Furthermore, less significant changes of water yield generation indicated in the study area during intermonsoon one (March - April), intermonsoon two (September - October) as well as Northeast monsoon (May-August).

The results show a substantial increase of about $38.19 \%$ in oil palm from 2000 to 2010. Similarly, forest and water body were decreased significantly to about $46.34 \%$ and $13.31 \%$ respectively from 2000 to 2010 . This result is in line with (Keleş, 2018), which state that the usual hydrological cycle of surface runoff, groundwater quality and quantity, stream water quality, soil infiltration, streamflow, evapotranspiration, and interception will vary as the forest decreases. The land use changes have been analysed and its influence on water yield was established using the Soil Water Assessment Tools model

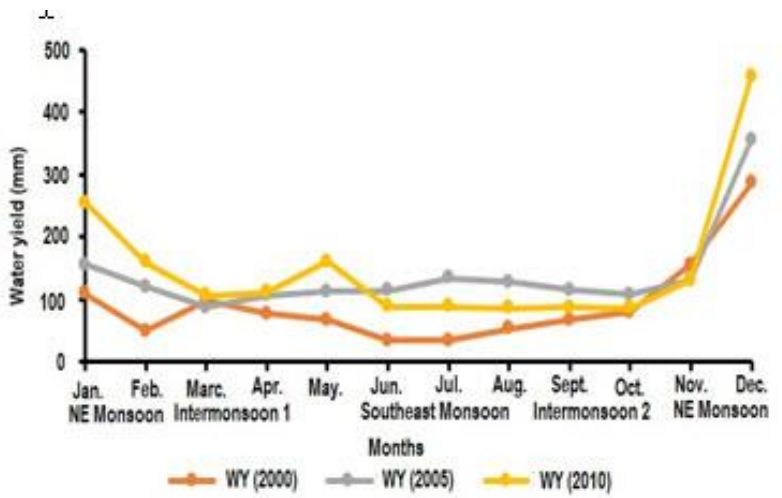

Figure. 5: Analysis of water yield

\section{CONCLUSION}

The satellite-based technology proved the capability of addressing the effects of land-use changes on water yield using Landsat ETM+ for the year 2000, 2005 and 2010 to analyse the land-use changes on water yield. Quantitative and qualitative assessment to investigate the land-use changes from forest to oil palm for the year 2000, 2005 and 2010 was carried out. The analyze shows substantial changes in the forest, oil palm as well as a water body. The results indicate that land-use changes due to the conversion of forest to oil palm may lead to the changes in the hydrological cycle of the area, which make the water yield increase by $1.93 \%$ between 2000 and 2010 . Therefore, this 
finding can assist in future land use policy and management of water resources. Furthermore, it will significantly contribute to the realization of sustainable development goal (SDG) 6 of the united nations, which stress the need to bring to an end the problem of water scarcity. Though, there will be an improvement in the future work to incorporate future land-use changes and climate variability on water yield

\section{ACKNOWLEDGEMENTS}

This study is part of Universiti Teknologi Malaysia (UTM) High Impact Research (HIR) on Satellite-based Spatio-temporal LULC Analysis to Water Yields (ref: Q.J130000.2409.04G44). Facilities used at the Geoscience and Digital Earth Centre (INSTeG), UTM as for this research commended. The authors acknowledge the Earth Resources observation system (EROS) Data centre of the United States Geological Survey (USGS) and the National Aeronautics and Space Administration (NASA) for the satellite data provided for the study.

\section{REFERENCES}

Fahey, B., Ekanayake, J., Jackson, R., Fenemor, A., Davie, T. and Rowe, L. 2010. 'Using the Watyield water balance model to predict catchment water yields and low flows', Journal of Hydrology New Zealand, 49(1), pp. 35-58.

Kahlerras, M. 2018: 'Modeling water supply and demand for effective water management allocation in Mazafran basin (north of Algeria)'. Arabian Journal of Geosciences.

Keleş, S. 2018: 'An Assessment of Hydrological Functions of Forest Ecosystems to Support Sustainable Forest Management an Assessment of Hydrological Functions of Forest Ecosystems', Journal of Sustainable Forestry. Taylor \& Francis, 0(0), pp. 1-22.

Lei, C. and Zhu, L. 2018: 'Climate Risk Management Spatiotemporal variability of land use / land cover change (LULCC) within the Huron River: E ff ects on stream fl ows', 19(August 2017), pp. 35-47.

Mahmud, M. R., Hashim, M., Mahmud, M. R. and Hashim, M. 2010: 'Determination of forest water yield in Malaysian tropical watershed using calibrated satellite-based rainfall data Determination of Forest Water Yield in Malaysian Tropical Watershed Using Calibrated Satellite-based Rainfall Data', (January 2015).

Marengo, J. A., Jr, C. A. S., Thonicke, K. and Burton, C. 2018. 'Changes in Climate and Land Use Over the Amazon Region: Current and Changes in Climate and Land Use Over the Amazon Region: Current and Future Variability and Trends', (December).

Musa, S. I. and Hashim, M. 2017: 'Urban Growth Assessment and Its Impact On Deforestation In Bauchi Metropolis, Nigeria Using Remote Sensing And Gis Techniques', 12(6), pp. 19071914.

Pervez, S. and Henebry, G. M. 2015. 'Journal of Hydrology: Regional Studies Assessing the impacts of climate and land use and land cover change on the freshwater availability in the
Brahmaputra River basin \&a', Journal of Hydrology: Regional Studies. Elsevier B.V., 3, pp. 285-311.

Rizaludin Mahmud, M. and Hashim, M. 2010. 'Determination of forest water yield in Malaysian tropical watershed using calibrated satellite-based rainfall data', CSSR 2010 - 2010 International Conference on Science and Social Research, (Cssr), pp. 798-803.

Shiferaw, H., Gebremedhin, A., Gebretsadkan, T. and Zenebe, A. 2018. 'Modelling hydrological response under climate change scenarios using SWAT model: the case of Ilala watershed, Northern Ethiopia', Modeling Earth Systems and Environment. Springer International Publishing, 0(0), p. 0.

Shukla, S. and Gedam, S. 2018. 'Assessing the impacts of urbanization on hydrological processes in a semi-arid river basin of Maharashtra, India', Modeling Earth Systems and Environment. Springer International Publishing, 0(0), p. 0.

Sperling, J. B. and Ramaswami, A. 2017. 'Cities and "BudgetBased" Management of the Energy-Water-Climate Nexus: Case Studies in Transportation Policy, Infrastructure Systems , and Urban Utility Risk Management', 0(0).

Talbot, C. J., Bennett, E. M., Cassell, K., Hanes, D. M., Minor, E. C., Paerl, H., Raymond, P. A., Vargas, R., Vidon, P. G., Wollheim, W. and Xenopoulos, M. A. 2018. 'The impact of flooding on aquatic ecosystem services', Biogeochemistry. Springer International Publishing, 141(3), pp. 439-461.

Wang, H., Xu, W., Zhang, M., Cui, L. and Yu, X. 2018. 'Effects of forest on mean annual runoff in North China', Polish Journal of Environmental Studies, 27(2), pp. 889-896.

Wang, L., Zhang, J., Liu, P., Choo, K. K. R. and Huang, F. 2017. 'Spectral-spatial multi-feature-based deep learning for hyperspectral remote sensing image classification', Soft Computing. Springer Berlin Heidelberg, 21(1), pp. 213-221.

Yildirim, Ü., Erdoğan, S. and Uysal, M. 2011. 'Changes in the Coastline and Water Level of the Akşehir and Eber Lakes Between 1975 and 2009', Water Resources Management, 25(3) pp. 941-962.

Yu, G., Wright, D. B., Zhu, Z., Smith, C. and Holman, K. D. 2019. 'Pirocess-based flood frequency analysis in an agricultural watershed exhibiting nonstationary flood seasonality', 2, pp. 2225-2243.

Revised August 2019 